\title{
Differences in Cyclic Fatigue Resistance at Apical and Coronal Levels of Reciproc and WaveOne New Files
}

\author{
Ana Arias, DDS, PbD, Juan J. Perez-Higueras, DDS, and José C. de la Macorra, MD, DDS, PhD
}

\begin{abstract}
Introduction: Recent improvements in alloys, kinematics, and concepts have been combined to increase the cyclic fatigue resistance of nickel-titanium (NiTi) instruments. The aim of this study was to compare the cyclic fatigue resistance of new M-Wire reciprocating WaveOne (Dentsply Maillefer, Ballaigues, Switzerland) and Reciproc (VDW GmbH, Munich, Germany) files at 2 levels. Methods: Sixty Reciproc and 60 WaveOne new files were fixed to a specifically designed device and tested in tempered steel canals with a $3-\mathrm{mm}$ radius and a $60^{\circ}$ angle of curvature. The motor used was programmed as defined by each manufacturer, and the specific reciprocating motion was followed. Thirty files of each brand were tested at $5 \mathrm{~mm}$, and 30 were tested at $13 \mathrm{~mm}$ from their tips. The time to failure was registered. Weibull analysis was used to calculate the mean life, beta, and eta parameters. Results: The probability of the mean life was higher for Reciproc than WaveOne files at both levels, with the probability of the Reciproc mean life being $62 \%$ higher than that of WaveOne at $5 \mathrm{~mm}$ from the tip and $100 \%$ higher at $13 \mathrm{~mm}$ (all statistically significant). The probability of the mean life was higher at $5 \mathrm{~mm}$ than at $13 \mathrm{~mm}$ in both systems. The results may have been partially conditioned by the different motions that manufacturers propose for each system. Conclusions: Reciproc files were more resistant to cyclic fatigue than WaveOne files at both distances from the tip. Both systems had greater cyclic fatigue resistance at 5 $\mathrm{mm}$ than at $13 \mathrm{~mm}$ from the tip. (J Endod 2012;38:1244-1248)
\end{abstract}

\section{Key Words}

Reciproc, reciprocation, WaveOne, Weibull

From the Department of Conservative Dentistry, School of Dentistry, Complutense University, Madrid, Spain.

Address requests for reprints to $\mathrm{Dr}$ José C. de la Macorra, Department of Conservative Dentistry, School of Dentistry, Complutense University, Plaza Ramon y Cajal s/n, Ciudad Universitaria, 28040 Madrid, Spain. E-mail address: macorra@ odon.ucm.es

0099-2399/\$ - see front matter

Copyright ( 2012 American Association of Endodontists. http://dx.doi.org/10.1016/j.joen.2012.05.022
$\mathrm{N}$ ickel-titanium (NiTi) rotary files have become a standard tool with which to shape root canals (1) because of their high flexibility and cutting ability (2) and because they create centered preparations more rapidly $(3,4)$. However, they tend to unexpectedly break because of cyclic fatigue (CF), which is induced by the alternating tension-compression cycles to which they are subjected when flexed in the maximum curvature region of the canal and rotated (5).

Conventional statistical approaches are frequently used to analyze the CF of materials in dentistry. Nevertheless, it has to be considered that materials fail as a consequence of the growth of cracks that originate in the surface or internal flaws (6-9) because crack extension occurs when the stored elastic energy (mechanical energy) released during extension just exceeds the energy required to form new surfaces (surface energy) (10). Because the changing distribution of flaws is responsible for the variability in $\mathrm{CF}(8)$, conventional approaches do not appropriately reflect the distribution of data. A more accurate description can be derived by determining the Weibull distribution, which is the ability to deal with cumulative processes causing fatigue by crack generation or the alteration of the preexisting material's defects measured along time $(9,11-15)$. This method allows one to work with extremely small samples, provides a simple and useful graphic plot, and applies when there are multiple similar opportunities to fail and the interest is in the first failure. It is the "weakest link in the chain" distribution (6).

Weibull risk-of-rupture analysis is a widely accepted model for material and structural evaluation (10) and is the leading method in the world for fitting and analyzing life data (6). Although it can be of particular value in dental applications (9), it has not been used to study the CF of endodontic instruments. It has been used in endodontics-related research to study the strain-life relationships of NiTi rotary instruments (16), the properties of endodontic post materials (17-19), the bond strength between the fiber post and root dentin (20), the risk of failure among endodontically treated teeth (21), and the mechanical longevity of post and core restorations (22).

Three major changes have been combined to make NiTi instruments safer: improved alloys, different movements, and new concepts of use. M-Wire is an NiTi alloy that increases the resistance to CF almost 4-fold (23). A different motion, based on the balanced force technique (24), was proposed using an F2 Protaper (Dentsply Maillefer, Ballaigues, Switzerland) instrument in reciprocation (25), which causes less CF than clockwise rotation $(26,27)$. Finally, a new concept proposes the use of a "singleuse, single-file system to shape the root canal completely from start to finish" (28). Reciproc (VDW GmbH, Munich, Germany) and WaveOne (Dentsply Maillefer) files are the only 2 M-Wire reciprocating "One File Endo" systems that have been developed.

The use of a single file to shape the whole canal challenges the concept of an endodontic instrument not working for itself but rather preparing the canal for the following instrument. When using the recently proposed shaping concept, a new consideration should be taken into account-the fact that the surface contact between the file and the canal increases. Because CF resistance could vary along the file, the probability of breakage could be different in any specific region of the instrument. This information seems to be useful to practitioners who take special care during the shaping procedure of the canal in the specific areas where the weaker part of the file is intended to work (29). Therefore, the aim of this study was to compare the $\mathrm{CF}$ resistance of Reciproc and WaveOne files at the coronal $(13 \mathrm{~mm})$ and apical (5 mm) levels. 


\section{Files}

\section{Materials and Methods}

Reciproc has an S-shaped cross-section. WaveOne has a modified convex triangular cross-section at the tip end and a convex triangular cross-section at the coronal end (28). One hundred twenty new files were tested: 60 primary WaveOne files (tip diameter: $0.25 \mathrm{~mm}$, variable taper: $8 \%$ at D1 and 5.5\% at D16) and 60 R25 Reciproc files (tip diameter: $0.25 \mathrm{~mm}$; variable taper: $8 \%$ at D1 and 3\% at D16). Thirty of each brand were tested at $5 \mathrm{~mm}$ from the tip (Reciproc at $5 \mathrm{~mm}$ [RE-5] and WaveOne at $5 \mathrm{~mm}$ [WO-5]), and 30 of each brand at $13 \mathrm{~mm}$ (Reciproc at $13 \mathrm{~mm}$ [RE-13] and WaveOne at $13 \mathrm{~mm}$ [WO-13]). Diameter measurements (in millimeters) at the tested lengths were W0-5: 0.62, WO-13: 1.06, RE-5: 0.62, and RE-13: 0.96.

\section{GF Test Device}

A device was fabricated to test CF at different levels (Fig. 1). It had 2 platforms that were designed to adjust positions in the 3 axes of space (Fig. 1A). One (x-axis) was used to fix the dental handpiece. This platform slid back and forth on a twisted spindle maneuvered by a knob approaching or moving away from the vertical support of the second platform. This second platform (y-and z-axes) had 2 knobs, each of which allowed for the adjustment of the vertical (y-axis) or the depth (z-axis) positions of the canals by displacing a hardened stainless steel piece with 11 carved open semicanals (Fig. $1 B$ white arrows) with diameters ranging from 0.4 to $1.4 \mathrm{~mm}$ in $0.1-\mathrm{mm}$ steps. Their depth was 0.1 $\mathrm{mm}$ greater than their width.

The entrance to the canals was vertical (Fig. $1 B$ red arrow). At 5 $\mathrm{mm}$ from these entrances (Fig. $1 B)$, the canal curved $\left(60^{\circ}\right.$ angle, $3-\mathrm{mm}$ radius) (Fig. $1 B$ and $C$ ). A swiveling, grooved stainless steel top face cover allowed for visualization of the files while rotating in the canal and served to protect the operator (Fig. 1B).

\section{Positioning and Testing of Files}

The canal selected was immediately wider (to the nearest $0.1 \mathrm{~mm}$ ) than the diameter of the file at the entrance of the canal. The canal of 0.8-mm width was used to test RE-5 and WO-5, and the 1.4-mm wide canal was used to test RE-13 and W0-13 (Fig. 1B). Files were placed in the handpiece and inserted into the selected canal. The top face cover was swung and secured. Both the canal and the file were lubricated with synthetic oil (Singer All-Purpose Oil; Singer Sewing Company, Barcelona, Spain) to minimize friction.

The files were operated in the VDW SILVER motor (VDW GmbH) with each recommended program (ie, Reciproc files with the "RECIPROC ALL" mode and WaveOne with the "WAVEONE ALL" mode). A recent report (30) claims that this resulted in $150^{\circ}$ counterclockwise and then $30^{\circ}$ clockwise rotation for Reciproc and $170^{\circ}$ counterclockwise and then $50^{\circ}$ clockwise rotation for WaveOne.

The motor and a 1/100-second chronometer were activated at the same time. The file was monitored through the face cover during the test. The chronometer was manually stopped at the moment of fracture, and the time to fracture was registered.

\section{Statistical Analysis}

Weibull analysis (Weibull++ 7; ReliaSoft Corporation, Tucson, AZ) was used to calculate the following parameters and their 95\% confidence interval for each group:

1. The mean life (in seconds): The expected or average time to failure

2. The beta, slope, or shape parameter (dimensionless): Its values are equal to the slopes of the regressed lines in the Weibull probability plot (31). Different slopes imply different classes of failure modes and are related to the quality of the design of the material.

3. The eta, characteristic life, or scale parameter (in seconds): The expected time that $63.2 \%$ of the files will reach without breakage (ie, the probability of failure being 0.63 at this time)

\section{Results}

The distribution of unreliability (ie, the probability of failure) versus time per group is shown in Figure 2. Table 1 presents the results for beta and eta parameters and the mean life and their $95 \%$ confidence intervals. When the mean life was compared between the types of files,

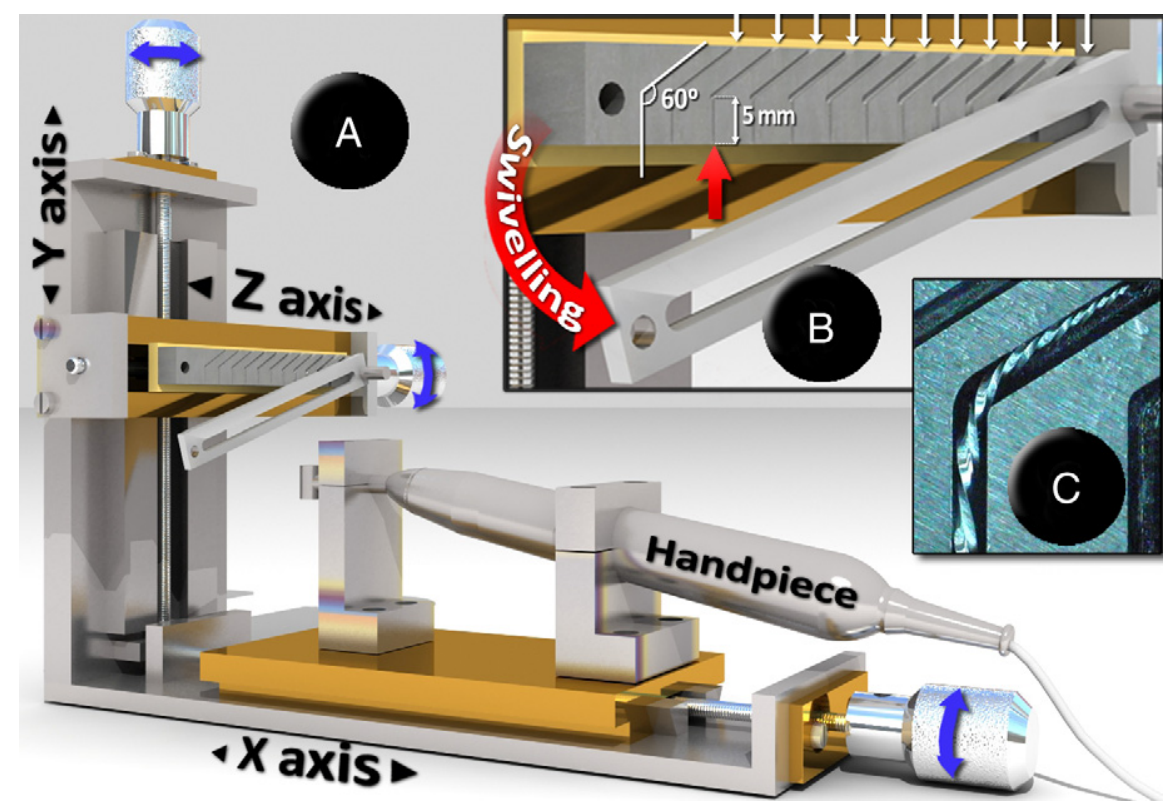

Figure 1. CF testing device. (A) General view: 3 axes are shown. (B) Swiveling motion of grooved stainless steel top face cover and carved open semicanals (white arrows). The red arrow points to the entrance of a canal. $(C)$ The bending point of a file before testing. 


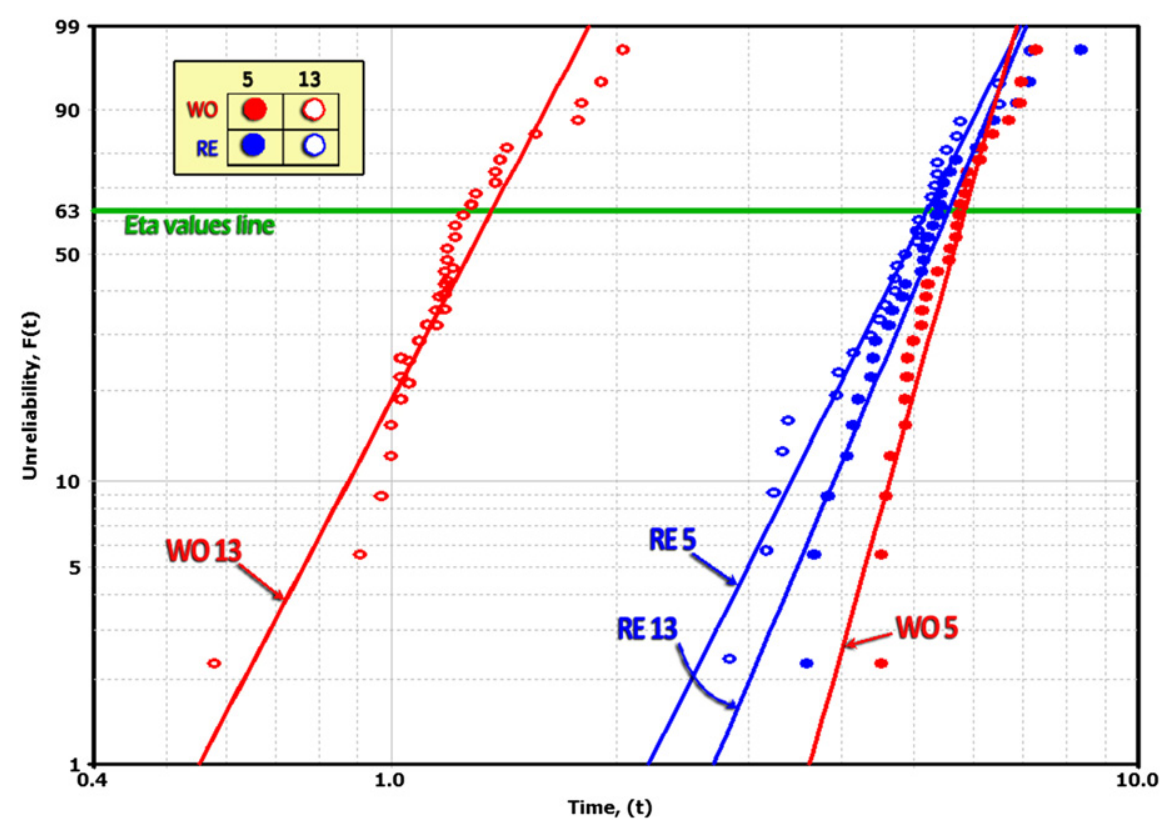

Figure 2. Weibull probability distribution per groups. The vertical scale in ordinates is unreliability (ie, the probability of failure). Time (seconds) is represented in the abscissa. The horizontal green line on the plot represents eta (ie, the time [seconds] at which $63.2 \%$ of the files will have failed). Note the logarithmic scale in both axes.

the probability that Reciproc files would last longer than WaveOne files was $62.4 \%$ (not statistically significant) at $5 \mathrm{~mm}$ from the tip and $99.9 \%$ (statistically significant) at $13 \mathrm{~mm}$. When the mean life at different distances from the tip was compared within the same type of file, the probability that RE-5 would last longer than RE-13 was $72.6 \%$ (statistically significant), whereas the probability that WO-5 would last longer than WO-13 was $99.9 \%$ (statistically significant).

\section{Discussion}

The results of the present study showed that all beta values are higher than 5.1 for both brands and both distances to the tips, indicating a steep slope (Fig. 2). The steeper the slope for a material is, the smaller the variation in the time to failure is and the more predictable the results are. A theoretical vertical line in the Weibull plot would imply perfect design, quality control, and production, whereas a theoretical horizontal line would mean extreme variability and would indicate that files could break with the same probability at any time (6). The beta value and $95 \%$ confidence intervals for R-5 denote a steeper slope than for R-13, W0-5, and W0-13, which indicates that Reciproc files are more predictable at $5 \mathrm{~mm}$ of the tip than in the coronal part and than WaveOne files in any of the tested sites.

TABLE 1. Weibull Parameters, the Mean Life, and Their $95 \%$ Confidence Intervals

\begin{tabular}{lllc}
\hline Group & Beta $(95 \% \mathrm{Cl})$ & Eta $(95 \% \mathrm{Cl})$ & Mean life $(95 \% \mathrm{Cl})$ \\
\hline RE-13 & $5.4(4.1-7)$ & $5.2(4.9-5.6)$ & $4.8(4.4-5.2)^{\mathrm{B}}$ \\
RE-5 & $9.6(7.4-12.5)$ & $5.9(5.6-6.1)$ & $5.6(5.3-5.9)^{\mathrm{A}}$ \\
WO-13 & $5.1(4-6.5)$ & $1.4(1.3-1.5)$ & $1.3(1.1-1.4)^{\mathrm{C}}$ \\
WO-5 & $6.4(5.1-8)$ & $5.6(5.2-6)$ & $5.2(4.8-5.6)^{\mathrm{A}, \mathrm{B}}$ \\
\hline
\end{tabular}

CI, confidence interval.

Reciproc (RE) and WaveOne (WO) files were tested at $5 \mathrm{~mm}$ (RE-5 and WO-5) and at $13 \mathrm{~mm}$ (RE-13 and WO-13) from the tip ( $n=30$ per group). Differences in the mean life between groups were significant if their $95 \%$ CI did not overlap. Superscript letters indicate homogeneous groups.
Eta values are homogeneous and vary between 5.2 and 5.9 seconds, except for W0-13, which is lower (1.4 seconds) (compare eta values [green line intersections in Fig. 2]). The mean life values (Table 1) follow the same pattern; WO-13 has a lower value (ie, 1.3) than the others. The CF resistance of WO- 13 was lower than that of the others.

Because a preparation technique using a single file with different motions had been proposed to shape the entire root canal (25), many studies have compared the use of F2 files in reciprocating motion with the conventional sequence of Protaper rotary files $(26,32-36)$. Significant differences have not been found in terms of the amount of extruded debris (32) or in apical transportation even in curved canals (33). However, significantly higher transportation in the coronal third was found when reciprocating movement was used (34). The main advantage of the new approach was that the working time was significantly reduced $(26,35)$ and that the CF life of $\mathrm{F} 2$ was longer when reciprocating motion was used compared with rotating motion (36). Aspects related to the root canal shape when using the WaveOne system have been studied $(37,38)$, but there is only 1 report on the CF of the 2 new systems (30).

The American National Standards Institute/American Dental Association standardized a protocol for testing the torsional load of .02 NiTi files used for hand instrumentation (39), but there are no standardized specifications to test the CF of rotary NiTi instruments. Until new standards that consider differences in the kinematics, designs, and alloys of new instruments are developed, well-designed reports on the physical characteristics of new files are necessary (40).

$\mathrm{CF}$ is a failure process associated with repetitive stress (5). The best way of reproducing this type of fatigue is repeating the movement for all tested files in the same, predefined curvature. Places where the file can bind should be avoided because additional torsional stress points will appear (40). Although the use of extracted teeth come close to clinical situations, they are not ideal for the analysis of CF because they are not standardized, and there may be other confounding factors (40). This study does not specifically intend to drive direct clinical conclusions 
but rather to test files in a controlled, repeatable, environment. In this way, confounding factors (eg, dentin, debris, and so on) are excluded, and results tend to approach the intrinsic properties of the files.

CF has been tested in artificial canals using plastic blocks, curved metal guiding slopes, tubes, and needles with different angles of curvature. One report analyzed the devices described in the literature and recommended the use of a method that would allow for the adaptation and fixation of the file to the canal to avoid oscillations that could affect the results (41).

We used a nontooth model. Canals were placed in hardened steel, and their design did not simulate clinical conditions. Because files have different diameters at different levels, a device suitable to test files at different levels should have different diameters, thus producing very similar testing conditions at any chosen point. The device used in this study had 11 canals with different diameters, which allowed for the testing of each file at any selected level with equivalent degrees of adaptation. To prevent oscillation of the files during testing, the device has a stainless steel top face cover.

Our method was used to analyze static CF. Files were tested at fixed lengths because our goal was to analyze CF at specific levels in each instrument. This type of method has been shown to yield lower results than dynamic methods (42) because axial movements of the files allow for the distribution of stresses (40). The only published report analyzing the CF resistance of Reciproc and WaveOne instruments used a dynamic setup (30). However, the authors also found that Reciproc files exhibited higher CF resistance values than WaveOne files.

We also found higher $\mathrm{CF}$ at apical levels than coronal ones. This may be because defects such as pits, metal strips, longitudinal scratches, and milling grooves have been found to be larger near the handle of the instrument than near the tip. The environmental scanning electron microscopy analysis of unused instruments consistently showed numerous surface defects that are very relevant to fatigue resistance (43).

The CF resistance of endodontic instruments is usually tested by recording the time until fracture in an artificial canal and transforming it to a number of cycles because NiTi files have been classically used in a rotary, clockwise motion (40-43). Some of the motors developed before Reciproc and WaveOne systems were available allow for the production of an oscillating movement (ie, a reciprocation) with symmetric clockwise and counterclockwise degrees of rotation. The amplitude of the oscillating angles of the recommended motion for Reciproc and WaveOne files are different toward each side $(30,44)$ for both brands tested in this research, which renders classic cycle concepts obsolete. In our protocol, the specific preprogrammed movement for each type of file was used, and the variable time was not transformed to a number of cycles. From a clinical perspective, it seems more useful to know the working time that the file can withstand inside the canal. However, there may be differences in cutting efficiency between the files that may translate to different working times clinically, but this was not studied.

The detection of differences in CF resistance between different parts of the instruments can be clinically relevant when a single-file system is used to shape the entire root canal because this information allows clinicians to be careful during the shaping procedure of the specific parts of the canal where the weaker parts of the files are intended to work.

\section{Acknowledgments}

The authors thank VDW and Maillefer for providing the instruments and files used in this study.

The authors deny any conflicts of interest related to this study.

\section{References}

1. Bird DC, Chambers D, Peters OA. Usage parameters of nickel-titanium rotary instruments: a survey of endodontists in the United States. J Endod 2009;35:1193-7.

2. Walia $\mathrm{H}$, Brantley WA, Gerstein $\mathrm{H}$. An initial investigation of the bending and torsional properties of nitinol root canal files. J Endod 1988;14:346-51.

3. Short JA, Morgan LA, Baumgartner JC. A comparison of canal centering ability of four instrumentation techniques. J Endod 1997;23:503-7.

4. Glosson CR, Haller RH, Dove SB, Delrio CE. A comparison of root-canal preparations using Ni-Ti hand, Ni-Ti engine-driven, and K-Flex endodontic instruments. J Endod 1995;21:146-51.

5. Sattapan B, Nervo GJ, Palamara JE, Messer HH. Defects in rotary nickel-titanium files after clinical use. J Endod 2000;26:161-5.

6. Abernethy RB. The New Weibull Handbook. Reliability \& Statistical Analysis for Predicting Life, Safety, Survivability, Risk, Cost and Warranty Claims, 4th ed. North Palm Beach, FL: Robert B. Abernethy; 2000.

7. Lambrighs K, Wevers M, Verlinden B, Verpoest I. A fracture mechanics approach to fatigue of heavily drawn steel wires. Procedia Eng 2011;10:3259-66.

8. Ravi Chandran KS, Chang P, Cashman GT. Competing failure modes and complex S$\mathrm{N}$ curves in fatigue of structural materials. Int J Fatigue 2010;32:482-91.

9. Quinn JB, Quinn GD. A practical and systematic review of Weibull statistics for reporting strengths of dental materials. Dent Mater 2010;26:135-47.

10. Kelly JR. Perspectives on strength. Dent Mater 1995;11:103-10.

11. Weibull W. A statistical distribution function of wide applicability. J Appl Mech 1951; $18: 293-7$

12. Bazant ZP. Scaling theory for quasibrittle structural failure. Proc Natl Acad Sci U S A 2004;101:13400-7.

13. Warren PD. Fracture of brittle materials: effects of test method and threshold stress on the Weibull modulus. J Eur Ceram Soc 2001;21:335-42.

14. McCabe JF, Carrick TE. A statistical approach to the mechanical testing of dental materials. Dent Mater 1986;2:139-42.

15. Gerds TA, Qvist V, Strub JR, Pipper CB, Scheike TH, Keiding N. Failure time analysis. In: Lesaffre E, Feine J, Leroux B, Dominique Declerck D, eds. Statistical and Methodological Aspects of Oral Health Research. Chichester, West Sussex, UK: John Wiley \& Sons, Ltd; 2009:259-77.

16. Cheung GSP, Darvell BW. Fatigue testing of a NiTi rotary instrument. Part 1: strainlife relationship. Int Endod J 2007;40:612-8.

17. Stewardson DA, Shortall AC, Marquis PM, Lumley PJ. The flexural properties of endodontic post materials. Dent Mater 2010;26:730-6.

18. Dakskobler A, Jevnikar P, Oblak C, Kosmac T. The processing-related fracture resistance and reliability of root dental posts made from Y-TZP. J Eur Ceram Soc 2007; 27:1565-70.

19. Dayalan M, Jairaj A, Nagaraj K, Savadi R. An evaluation of fracture strength of zirconium oxide posts fabricated using CAD-CAM technology compared with prefabricated glass fibre posts. J Indian Prosthodont Soc 2010;10:213-8.

20. Castellan CS, Santos-Filho PC, Soares PV, Soares CJ, Cardoso PE. Measuring bond strength between fiber post and root dentin: a comparison of different tests. J Adhes Dent 2010;12:477-85.

21. Lin CL, Chang YH, Pa CA. Estimation of the risk of failure for an endodontically treated maxillary premolar with MODP preparation and $\mathrm{CAD} / \mathrm{CAM}$ ceramic restorations. J Endod 2009;35:1391-5.

22. Huysmans MC, van der Varst PGT. Mechanical longevity estimation model for postand-core restorations. Dent Mater 1995;11:252-7.

23. Johnson E, Lloyd A, Kuttler S, Namerow K. Comparison between a novel nickel-titanium alloy and 508 nitinol on the cyclic fatigue life of ProFile 25/.04 rotary instruments. J Endod 2008;34:1406-9.

24. Roane JB, Sabala CL, Duncanson MG Jr. The "balanced force" concept for instrumentation of curved canals. J Endod 1985;11:203-11.

25. Yared G. Canal preparation using only one Ni-Ti rotary instrument: preliminary observations. Int Endod J 2008;41:339-44.

26. You S-Y, Bae K-S, Baek S-H, Kum K-Y, Shon W-J, Lee W. Lifespan of one nickel-titanium rotary file with reciprocating motion in curved root canals. J Endod 2010;36:1991-4.

27. Varela-Patiño P, Ibanez-Parraga A, Rivas-Mundina B, Cantatore G, Otero XL, MartinBiedma B. Alternating versus continuous rotation: a comparative study of the effect on instrument life. J Endod 2010;36:157-9.

28. Webber J, Machtou P, Pertot W, Kuttler S, Ruddle C, West J. The WaveOne single-file reciprocating system. Roots 2011;1:28-33.

29. Castellucci A. Schilder's technique for shaping the root canal system. In: Castellucci A, ed. Endodontics. Florence, Italy: Tridente; 2005:467.

30. Kim H-C, Kwak S-W, Cheung GS-P, Ko D-H, Chung S-M, Lee W. Cyclic fatigue and torsional resistance of two new nickel-titanium instruments used in reciprocation motion: Reciproc versus WaveOne. J Endod 2012;38:541-4.

31. Reliasoft. Life Data Analysis Reference. Tucson, AR: Reliasoft Publishing; 2005.

32. De-Deus G, Brandao MC, Barino B, Di Giorgi K, Fidel RA, Luna AS. Assessment of apically extruded debris produced by the single-file ProTaper F2 technique under 
reciprocating movement. Oral Surg Oral Med Oral Pathol Oral Radiol Endod 2010; 110:390-4

33. You SY, Kim HC, Bae KS, Baek SH, Kum KY, Lee W. Shaping ability of reciprocating motion in curved root canals: a comparative study with micro-computed tomography. J Endod 2011;37:1296-300.

34. Paque F, Zehnder M, De-Deus G. Microtomography-based comparison of reciprocating single-file F2 ProTaper technique versus rotary full sequence. J Endod 2011; 37:1394-7.

35. Varela-Patino P, Martín-Biedma B, Rodriguez-Nogueira J, Cantatore G, Malentaca A, Ruiz-Pinón M. Fracture rate of nickel-titanium instruments using continuous versus alternating rotation. Endod Prac Today 2008;3:193-7.

36. De-Deus G, Moreira EJ, Lopes HP, Elias CN. Extended cyclic fatigue life of F2 ProTaper instruments used in reciprocating movement. Int Endod J 2010;43: $1063-8$.

37. Berutti E, Paolino DS, Chiandussi G, et al. Root canal anatomy preservation of WaveOne reciprocating files with or without glide path. J Endod 2012;38:101-4.
38. Berutti E, Chiandussi G, Paolino DS, et al. Effect of canal length and curvature on working length alteration with WaveOne reciprocating files. J Endod 2011;37: $1687-90$.

39. New American Dental Association Specification no. 28 for endodontic files and reamers. Council on Dental Materials and Devices. J Am Dent Assoc 1976;93:813-7.

40. Yao JH, Schwartz SA, Beeson TJ. Cyclic fatigue of three types of rotary nickel-titanium files in a dynamic model. J Endod 2006;32:55-7.

41. Plotino G, Grande NM, Cordaro M, Testarelli L, Gambarini G. A review of cyclic fatigue testing of nickel-titanium rotary instruments. J Endod 2009;35:1469-76.

42. Rodrigues RCV, Lopes HP, Elias CN, Amaral G, Vieira VTL, De Martin AS. Influence of different manufacturing methods on the cyclic fatigue of rotary nickel-titanium endodontic instruments. J Endod 2011;37:1553-7.

43. Pirani C, Cirulli PP, Chersoni S, Micele L, Ruggeri 0, Prati C. Cyclic fatigue testing and metallographic analysis of nickel-titanium rotary instruments. J Endod 2011;37: $1013-6$.

44. Ruddle CJ. The shaping movement. Wave of the future. Endod Prac 2011;4:64. 